\title{
ANÁLISIS DE LA CONSTRUCCIÓN DE LAS FIGURAS EQUINAS EN EL ARTE RUPESTRE DEL VALLE DE GUASAPAMPA COMO EVIDENCIA DE UNA APROPIACIÓN SIMBÓLICA DEL CONQUISTADOR (CÓRDOBA, ARGENTINA)
}

\author{
ANALYSIS OF THE CONSTRUCTION OF HORSE FIGURES IN ROCK ART OF \\ GUASAPAMPA VALLEY AS EVIDENCE OF THE SIMBOLIC APPROPRIATION \\ OF THE SPANISH CONQUISTADOR (CÓRDOBA, ARGENTINA)
}

\begin{abstract}
Andrea Recalde ${ }^{1}$
Este trabajo tiene como objetivo comprender el papel de los motivos equinos documentados en el arte rupestre de la porción meridional del valle de Guasapampa (Córdoba, Argentina). El análisis de las características de las representaciones del área y, fundamentalmente una perspectiva comparativa de la resolución de las formas de camélidos y equinos, constituye la línea de indagación que permite plantear que el caballo, como rasgo particularizante de los españoles, es significado en el marco de creencias y parámetros prehispánicos. Se entiende así que la construcción del nuevo significante en base a un referente conocido constituye una estrategia de apropiación simbólica del otro o, en otros términos, la objetivación de una respuesta al nuevo contexto generado por la conquista hispana. El arte rupestre se convierte en la vía material que permite "traducir" lo novedoso en estrategias de acciones propias y adecuadas a la cosmovisión de los grupos que ocupaban estacionalmente el valle.
\end{abstract}

Palabras claves: figuras equinas, apropiación simbólica, valle de Guasapampa.

The aim of this paper is to understand the role of horse motifs that have been identified in rock art from the southern section of the Guasapampa valley (Córdoba, Argentina). The analysis of rock art characteristics through a comparative perspective focused on the form of camelid and horse designs allows us to propose that the typically Hispanic horse motif was defined under pre-Hispanic parameters and belief contexts. The construction of new significants based on a pre-Hispanic group strategy could be considered a symbolic appropriation of the Other. As such, the rock art becomes a material means for pre-Hispanic groups occupying the Guasapampa valley, to "translate" the new Spanish feature into their own beliefs and strategies.

Key words: Horse designs, symbolic appropriation, Guasapampa valley.

En este trabajo se analizan algunas figuras que, por su forma y diseño, aluden directamente a lo español y a la presencia del conquistador en la región central de las Sierras de Córdoba (Argentina). Así, en dos de los 36 sitios con arte rupestre del sur del valle de Guasapampa, emplazado en el corredor oeste de las Sierras Grandes, se documentaron dos paneles que se destacan por la presencia de motivos equinos. A diferencia de lo que sucede en sitios ubicados en otras regiones serranas cordobesas (i.e. Cerro Colorado en las Sierras del Norte, La Playa en el sector central de las Sierras Grandes y finalmente Casa Pintada y Cerro Piedra Bola al sur, en las sierras de Comechingones) la particularidad de esta área está determinada por la representación aislada del caballo y, en consecuencia, por la ausencia de la figura ecuestre, composición equino/ humano tan característica dentro del repertorio de motivos que identifica al arte rupestre originado a partir del contacto con el español y que ha sido fundamentalmente trabajado para la región andina bajo la denominación de arte rupestre postconquista, postcontacto o colonial (Fernández Distel 1992; Hernández Llosas 2001; Martínez y Arenas 2009; Querejazu Lewis 1992). A partir del estudio de las pinturas rupestres de la sección meridional del valle de Guasapampa se propone comprender cómo esta representación equina, en tanto elemento a partir del cual se identifica y reconoce la figura del otro, fue asimilada y modificada en base a los marcos de referencia de las comunidades indígenas locales, al tiempo que advertir una de las posibles respuestas simbólicas desencadenadas por y ante la conquista. En este sentido, se considera que todo nuevo

1 CONICET. Universidad Nacional de Córdoba. San José de Calasanz 597. Mendiolaza. Córdoba, Argentina. recaldema@yahoo.com.ar 
acontecimiento adquiere su significación siempre y cuando sea incorporado y analizado en un marco de concepciones tradicionales, que en otros términos implica que todo hecho novedoso es interpretado en base a creencias y pautas simbólicas propias. Es así que los cambios, generados por actores externos, se producen y se interpretan a partir de aquello que históricamente es considerado como válido y trascendente, proceso por el cual las circunstancias presentes se modifican y se alteran (v. gr. Hastorf 2003). Esto se origina porque, ante el intento de los grupos de reproducir las estructuras sociales (Bourdieu 2002), los nuevos acontecimientos y el contacto con nuevos actores ponen en juego categorías que tienen un fundamento histórico pero que, inevitablemente, generan las bases para modificar sus condiciones presentes, porque el contexto en el que se fundan las respuestas se ha modificado.

Por lo tanto, la primera acción y reacción de los grupos indígenas ante el invasor fue significar su llegada a partir de la puesta en práctica de una serie de categorías y creencias que permitieran su inclusión en el imaginario indígena. Esta continuidad de los sentidos (Cruz 2006) puede valorarse por la incorporación de un rasgo que es ajeno, en tanto conforma un elemento que identifica y distingue al otro, otorgándole un sentido que se ajusta al propio marco de referencia, a una forma propia de representar la realidad. En este contexto, esta acción es interpretada como una "apropiación simbólica del otro" (Arenas y Martínez 2009:23) objetivada por la inclusión de lo desconocido en los sentidos socialmente construidos.

Esta acción simbólica de despojar al elemento extraño de sus particularidades puede ser considerada también como una forma de resistencia a partir de la resemantización del mismo. El medio que sostiene esta estrategia o "arte de hacer" con el otro, es específicamente su significación en base a conceptos, creencias y sentidos propios (De Certeau 1999 [1979]). En concreto, esta significación de lo español en base a lo conocido es una manera de mantener las condiciones que sostienen el statu $q u o$, una respuesta que persigue la continuidad de esquemas simbólicos que son parte importante de la reproducción social de un grupo. La modificación de sus significantes occidentales e hispánicos constituye el medio para tal fin, una manera de enmarcar el acontecimiento en una categoría preexistente. Esta transformación y modificación operarían en la construcción del caballo en base a los elementos constitutivos del camélido y a la significación que este tiene en el imaginario indígena. Es precisamente la figura de este artiodáctilo la que actúa como categoría preexistente.

$\mathrm{El}$ arte rupestre fue una de las prácticas que generó el marco para esta elaboración del otro, para esta construcción de la otredad. En tal sentido se entiende que esta materialidad se constituye como un rasgo que participa activamente en la construcción social de la realidad en tanto se convierte en una vía que objetiva y permite un intento de "traducción" de lo novedoso en estrategias de acción propias y adecuadas a la cosmovisión de los grupos prehispánicos (Gallardo et al. 1990).

De esta manera, se observan las particularidades de las representaciones rupestres de la sección sur del valle de Guasapampa y, especialmente, de la subárea de Charquina, a fin de comprender como se inscriben las figuras de los equinos en un universo dominado por los motivos zoomorfos en general y los camélidos en particular. Al respecto, se analizan fundamentalmente los diseños de las figuras de los caballos, haciendo hincapié en los detalles de la resolución formal, a fin de compararlos con los cánones y patrones (sensu Aschero 1996) identificados en los diseños de camélidos del sector meridional del valle de Guasapampa, dado que esta vía proporciona elementos para advertir cómo y en base a qué se construye formalmente lo nuevo.

\section{Información Arqueológica y Documental sobre el Sur del Valle de Guasapampa}

\section{Características de la ocupación prehispánica}

El período Prehispánico Tardío, que abarca desde ca. 1.500 al 350 a.p., está caracterizado por el desarrollo de una gran movilidad desplegada en el marco de una economía mixta, en la cual se combinan la agricultura, la caza, la recolección y posiblemente el pastoreo de camélidos. Estas prácticas, habituales y esenciales para asegurar la reproducción social, involucran el traslado a microambientes que proporcionan diferentes recursos, como las pampas de altura (paisajes por encima de los $1.200 \mathrm{msm}$ en el que habitaban camélidos y cérvidos) o entornos chaqueños (Berberián et al. 2009).

Uno de estos ambientes chaqueños es el valle de Guasapampa que está inserto entre las sierras Pocho y las de Guasapampa y Serrezuela (occidente de las Sierras de Córdoba, Argentina; Figura 1). Se 


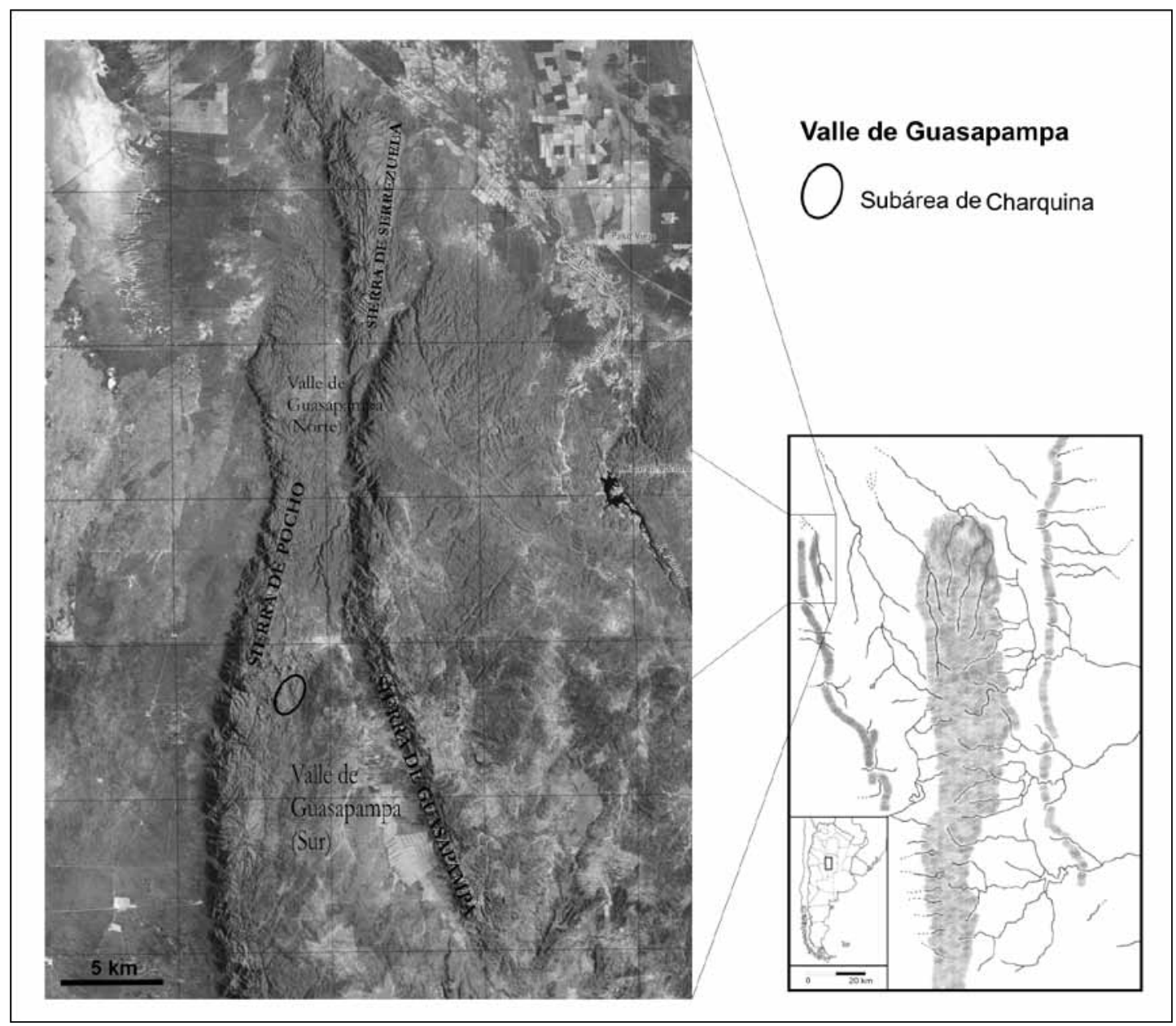

Figura 1. Ubicación del Valle de Guasapampa y de la subárea de Charquina. Localitation of Guasapampa valley and subarea of Charquina.

desarrolla en un dominio semidesértico, con un déficit hídrico que oscila entre los 300 a $550 \mathrm{~mm}$ anuales (Trillo 2010). Estas particularidades ambientales (escasas precipitaciones, concentradas en época estival, y escasa humedad ambiental) convierten a la zona en poco apta para la agricultura, situación que tiene su correlato arqueológico dado que no se ha detectado un patrón de ocupación vinculado con la explotación agrícola. No obstante, las características del ambiente permiten el desarrollo de especies arbóreas y arbustivas ricas en frutos silvestres, muchas de las cuales tuvieron importancia económica para los grupos indígenas del área (v.gr. algarrobo -Prosopis nigra y P. alba- y el chañar-Geoffrea decorticans).

En este sentido, los datos obtenidos en los trabajos de excavación realizados en cuatro sitios del sector sur del valle de Guasapampa, tres de los cuales presentan una asociación directa con paneles con arte rupestre, generaron un corpus de información que indica eventos repetidos de abandono y reocupación a lo largo de todo el Prehispánico Tardío. Los diferentes sitios fueron construidos y significados de manera transitoria por un número reducido de individuos, probablemente una unidad familiar, que gran parte del año habitaban los fondos de valle asociados a los espacios agrícolas. Las evidencias proporcionadas por los análisis arqueobotánicos (i.e. fitolitos de chañar y algarroba) y arqueofaunísticos (altas frecuencias de huevos de Rhea sp., cuyo período de anidación se acota desde fines de la primavera a mediados del verano) han permitido proponer que estos grupos realizaban sus actividades fundamentalmente durante la época estival (Recalde 2008-2009). En este marco, la ausencia en la estratigrafía de los 
sitios excavados de contextos asignados a grupos cazadores-recolectores, es decir anteriores al ca. 1.500 a.p., es lo que permite reforzar esta asignación tardía en la cronología local para la ocupación del sector y para la ejecución de los paneles.

A partir del ca. $1.360 \pm 60$ a.p. (LP 1812, carbón; Recalde 2008-2009), y con mayor intensidad desde

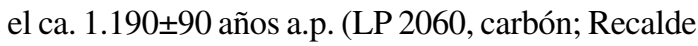
2008-2009), y hasta el ca. 390 \pm 60 años a.p. (LP 1709, carbón; Recalde 2008-2009) la porción meridional del valle fue incorporada dentro de los circuitos de movilidad de los grupos prehispánicos que habitaron la región central de las Sierras Centrales.

En estos contextos de ocupación y construcción de lugares y del paisaje el arte rupestre jugó un papel fundamental en la afirmación de las identidades de aquellas unidades familiares que reocupaban esos sitios. La repetición en el tiempo de motivos, diseños, temas y maneras de disponer y usar los paneles se convierten en la línea de evidencia que respalda esta continuidad en la forma de plasmar lo compartido por todas aquellas personas que se trasladaban a Guasapampa, pero también lo significativo e identitario para cada grupo (Recalde 2009). En este marco, los motivos zoomorfos y particularmente los camélidos son las figuras que estructuran y definen este repertorio.

\section{Guasapampa en las fuentes hispánicas}

La llegada de los españoles al sector central de la Argentina se produjo en 1544 con la primera entrada de exploración y fundación ocurrida por el norte de la actual provincia de Córdoba, al mando de Diego de Rojas. Entre esta fecha inicial y la fundación de la ciudad de Córdoba en 1573, se suceden cinco entradas que cubren distintas áreas del norte de la región.

La conquista y la instauración posterior del régimen colonial español impactaron sobre las prácticas sociales, económicas y culturales, generando la desestructuración del mundo indígena (Bixio 1998; Piana 1992). La reacción ante la imposición española fue aislada $y$, con el establecimiento del régimen legal de la colonia, fundamentalmente individual. En este sentido, los documentos hispánicos sólo indican la existencia de algunos focos menores de resistencia armada en la región con posterioridad a 1544, expresada sólo en episodios esporádicos y muy efímeros que no lograron ser efectivos a largo plazo, a punto tal que treinta años después de la fundación de la ciudad de Córdoba, ocurrida en 1573, no quedaba signo alguno de beligerancia en la región (Bixio y González Navarro 2003) ${ }^{1}$.

La información proporcionada por los documentos hispánicos ubica los contactos iniciales entre los grupos que ocuparon estacionalmente el valle de Guasapampa y el conquistador recién en 1573 con la llegada de Lorenzo Suárez de Figueroa. Es posible plantear como hipótesis que los caballos se hayan realizado dentro del jalón temporal delimitado por el arribo de los españoles a la región de Córdoba (1544) y la fundación de la ciudad (1573), dado que esta última fecha marca el momento a partir del cual se definieron los primeros padrones de indios y se repartieron las primeras encomiendas $y$, en consecuencia, se inició la desarticulación de las prácticas indígenas. Sin embargo, un dato a destacar es que la repartición de tierras y mano de obra involucró sólo la zona comprendida por Serrezuela y los valles de Salsacate y Soto, región colindante al valle de Guasapampa, porque allí se ubicaban pueblos de indios (González Navarro 2009). Esta información genera otra línea de contrastación que respalda la evidencia arqueológica recuperada en el sector a partir de la cual se infiere que el área objeto de estudio no presentaba, a la llegada de los españoles, un patrón de ocupación definido por la instauración de pueblos tardíos o de carácter residencial.

\section{Arte Rupestre de Guasapampa Sur}

Las características geomorfológicas del ambiente granítico que caracteriza al paisaje de Guasapampa generan numerosos soportes potenciales para la ejecución de paneles con representaciones rupestres. No obstante se puede observar una clara selección en cuanto a los tipos de sitios y sus características, al igual que una concentración de los paneles en determinadas zonas. Así, en la porción sur del valle de Guasapampa se han identificado siete subáreas, divididas en base a criterios fundados en cercanía espacial, características topográficas y toponimia local. Éstas son: Cerco de la Cueva, Charquina, Barranca Honda, La Pampita, Cerco Otto, Yaco Pampa y Cerco Rodríguez.

Un total de 36 sitios están emplazados en estas subáreas, con paneles que reúnen una cantidad de 807 motivos pintados y grabados, distribuidos entre figurativos y no figurativos. La particularidad del arte rupestre de Guasapampa es que, entre los 
primeros, se observa un claro predominio de los zoomorfos con el 72,1\% ( $\mathrm{n}=582)$, repertorio que, a pesar de estar conformado por varias especies de animales (reidos, camélidos, cérvidos, teidos), está mayoritariamente constituido por los camélidos con el 70,9\% ( $n=413)$.

Entre estos artiodáctilos se han documentado diferencias de diseño que han permitido distinguir cinco cánones que circulan entre las subáreas de la sección meridional del valle (Recalde 2009). Con el fin de evitar aquí una descripción de todas estas variaciones se caracteriza sólo el canon D, dado que sus particularidades permiten establecer comparaciones con las resoluciones formales de los equinos. Este canon se define por un perfil no absoluto ya que están indicadas las dos orejas y las cuatro patas (Figura 2). El diseño no respeta las proporciones del referente real debido a que su trazado se resuelve a partir de una forma simple y lineal, en la que las distintas partes del animal, es decir cola, cuerpo, cuello y cabeza, están ejecutadas como un continuo. Las extremidades se distribuyen de manera aleatoria y, en algunos casos, no guardan proporción con el tamaño del cuerpo. Pueden o no estar presentes los dedos del camélido. Este canon presenta un patrón, D1, con una resolución semejante en la cual se modifica la disposición del cuerpo ejecutado en base a líneas curvas.

En este contexto general, con un repertorio iconográfico dominado por estos artiodáctilos, se han identificado algunos motivos en la subárea de Charquina vinculados, por la relación con su referente formal, con la figura de equinos. Estas imágenes constituyen los únicos rasgos que dan cuenta de la presencia hispana en la sección sur del valle de Guasapampa.

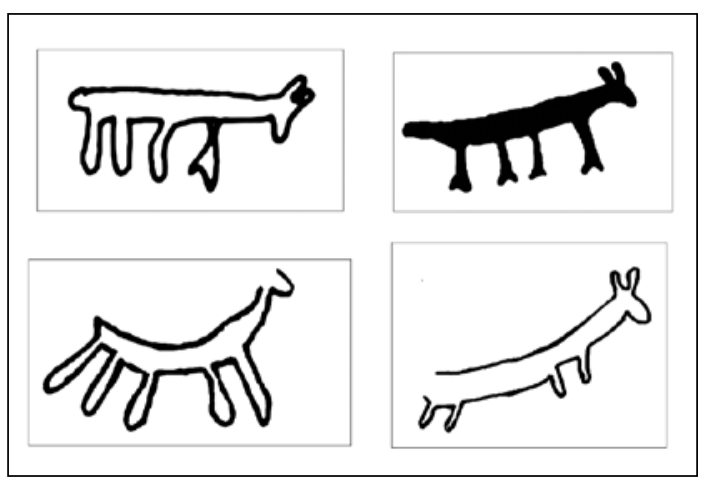

Figura 2. Canon D y patrones identificados en los camélidos Guasapampa sur.

Canon D and patterns identified in camelids from south Guasapampa.
Finalmente, los soportes seleccionados para la ejecución de los paneles generan un juego de visibilidad e invisibilidad de lo representado, que implica una doble situación respecto a la construcción del paisaje. No obstante en un alto porcentaje (56\%), dadas las particularidades del emplazamiento del panel o el tipo de soporte, los motivos sólo interpelan a aquellas personas que conocen su existencia, a partir de la construcción y ocupación cotidiana de esos lugares o sitios por medio de las prácticas desarrolladas en el marco de la ocupación estacional ocurrida durante el Prehispánico Tardío.

\section{Arte Rupestre de Charquina}

La subárea de Charquina está ubicada en el sector pedemontano oriental de las sierras de Pocho, en la cual se registra la máxima altura de la microrregión de Guasapampa con el cerro Orcosuni de 870 msm (Figura 1). Asimismo, está caracterizada por la presencia de algunos arroyos de marcado carácter estacional, muchos de los cuales sólo son desagües arenosos de las tierras altas que rompen la continuidad del bosque autóctono.

En Charquina (a partir de ahora $\mathrm{Ch}$ ) se documentó la mayor cantidad de sitios con representaciones rupestres de todo el sur del valle con un total de 15. En los paneles que integran la subárea se individualizaron 349 motivos, entre figurativos y no figurativos. A pesar de la variabilidad, Ch es un espejo de las particularidades registradas en toda la microrregión de Guasapampa, es decir, una tipología marcada por la importancia numérica de los zoomorfos. En este sentido, este grupo conforma el 63,8\% (n=221), dentro del cual se distingue un predominio de los camélidos por sobre las otras especies animales, con el 55,1\% $(\mathrm{n}=191$; Figura 3$)$.

En Ch se han reconocido las cinco resoluciones formales que circulan por las subáreas; no obstante, a diferencia de lo que sucede en otras, aquí el canon $\mathrm{D}$ es el dominante ya que representa el $66 \%(n=121)$. Este canon incluye dos variaciones o patrones (Aschero 1996) en los que se resuelve la figura del camélido, cuya diferencia radica en la forma del cuerpo dispuesto en "U", que genera una representación más estilizada del animal (Figura 2).

Los soportes seleccionados en esta subárea nuevamente repiten las particularidades observadas en toda la microrregión, es decir un juego entre la invisibilidad y la visibilidad de lo representado, pero 


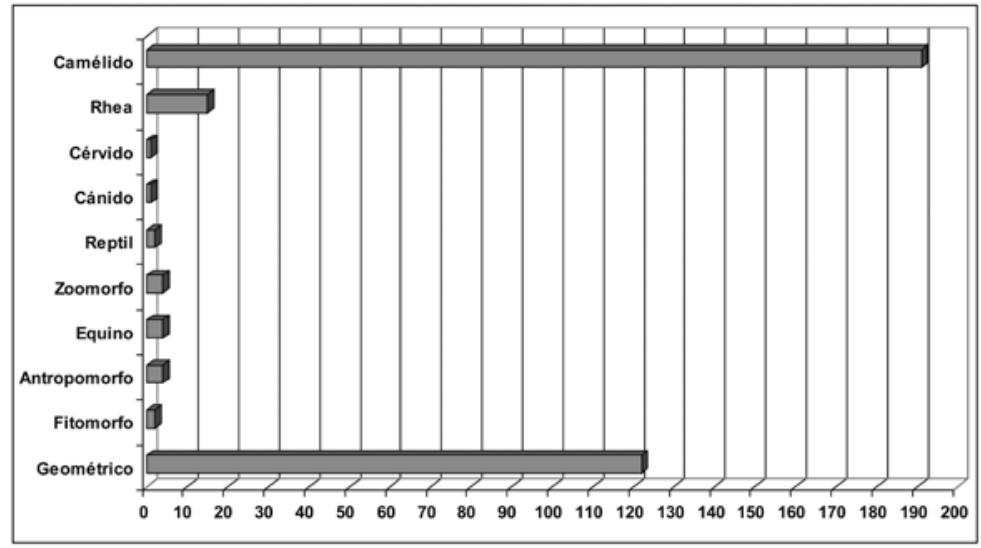

Figura 3. Tipos de motivos identificados en Charquina.

Motif types identified in Charquina.
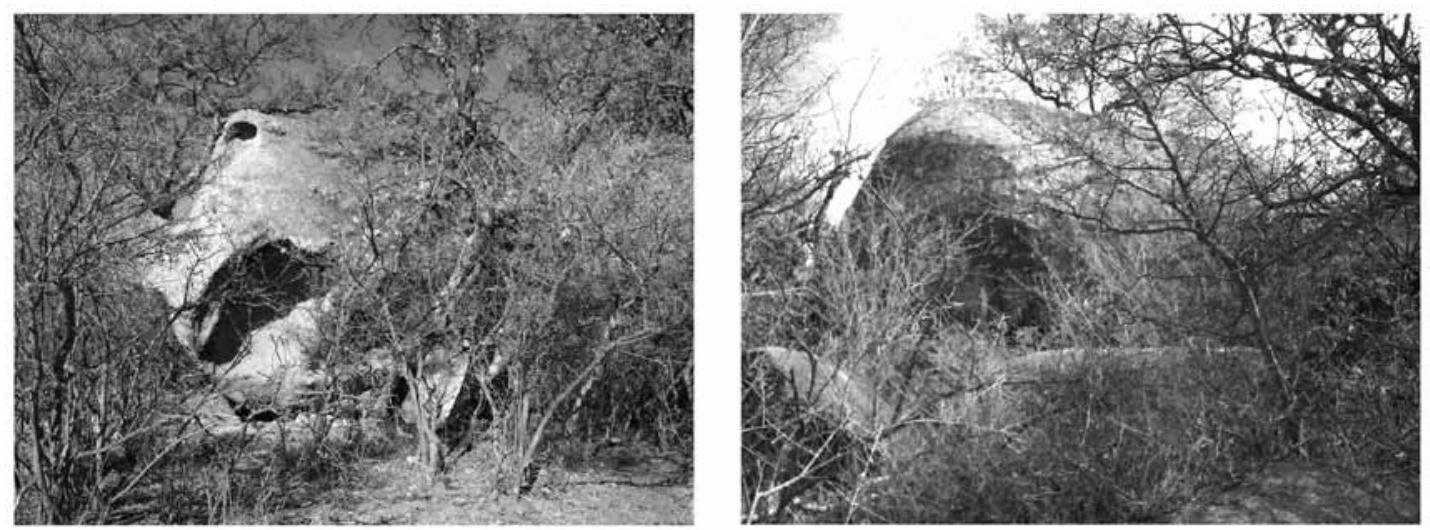

Figura 4. Detalle de las características de Ch9 (imagen izquierda) y Ch14 (imagen derecha).

Details of $\mathrm{Ch} 9$ (left) and Ch14 (right).

con un predominio en Ch de la primera situación con un $60 \%(n=9)$.

Dos sitios, Ch9 y Ch14, cuentan con representaciones que denotan lo hispánico. El primero de ellos es un bochón granítico de aproximadamente $10 \mathrm{~m}$ de diámetro por 3,5 $\mathrm{m}$ de alto (Figura 4), en el que se relevaron dos paneles. En la cara sur se identificó un pequeño abrigo rocoso con seis motivos blancos. Dos corresponden claramente a camélidos del canon A, tres pueden ser asignados a este referente dados sus elementos constitutivos y, finalmente, uno geométrico. La única asociación contextual es un molino plano localizado en la base del alero. En la cara norte de la formación se reconocieron dos representaciones, también en blanco. Una es un zoomorfo de carácter indefinido dada la mala conservación; en tanto la otra, como se verá en el apartado siguiente, tiene la clara forma de un equino. Ambos paneles permiten una observación participativa para todo aquel que circule por el paisaje.
En tanto, Ch14 es un tafón o tafone cuyas medidas son $8 \mathrm{~m}$ de diámetro y de apenas $0,80 \mathrm{~m}$ de altura en su interior (Figura 4). En el techo del abrigo se documentaron un total de 61 motivos en blanco y negro, ubicados en tres sectores del soporte (Figura 5), entre los que se distinguen zoomorfos y geométricos. Entre los primeros se destacan los camélidos con el $50 \%(n=30)$, reidos con el 4,83\% $(n=3)$, un teido y tres zoomorfos indefinidos. Los geométricos reúnen el $32,63 \%$ (n=21) y está conformado por líneas paralelas y cruzadas en un punto, líneas rectas elaboradas con puntos y círculos. El análisis de los camélidos permite diferenciar tres de los cinco cánones presentes en toda la microrregión de Guasapampa. Estos son el A y el B que reúnen, de manera relativamente equitativa, el 60\% $(n=18)$ $y$ el $D$ con el $40 \%(n=12)$.

En este panel son perceptibles diferencias en el conjunto tonal tanto entre los motivos blancos como entre los negros, situación que involucra a los 


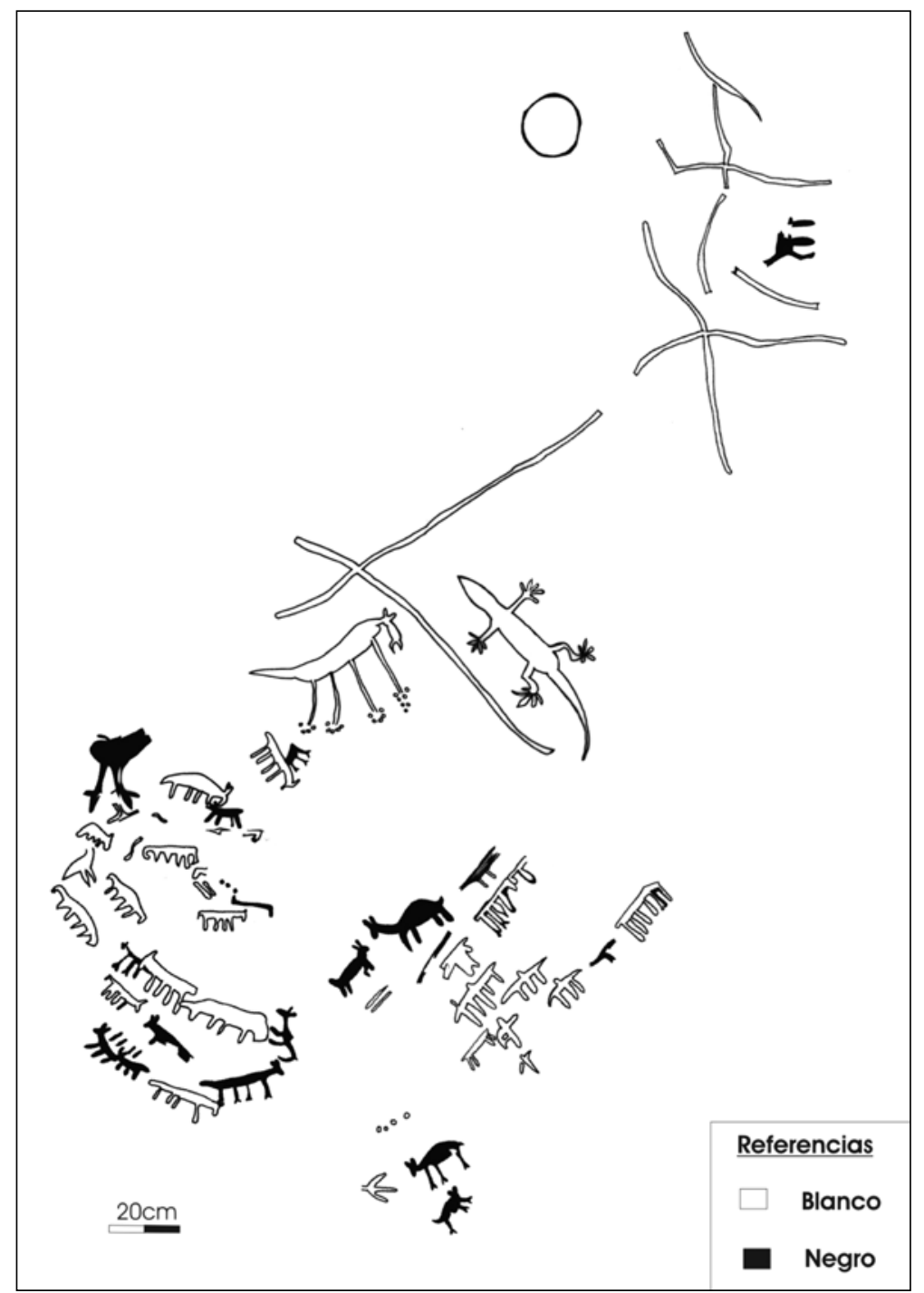

Figura 5. Detalle de uno de los paneles de Ch14 en el que se distinguen los diferentes motivos que lo componen. Detail of a panel from $\mathrm{Ch} 14$ which distinguishes the different motifs.

equinos que presentan un blanco más desvaído que algunos de los camélidos del panel. De la misma manera, se observan superposiciones e incluso un zoomorfo originalmente negro que indica un repintado blanco con una tonalidad semejante a los equinos, y también camélidos que pudieron ser ejecutados al mismo tiempo o ser también mantenidos mediante el repintado. Esta información autoriza a proponer momentos relativamente sincrónicos de ejecución, que indicarían una realización conjunta de los equinos con algunos camélidos y otras figuras zoomorfas del panel.

\section{Características de los caballos}

La figura de los equinos, definidos formalmente por el análisis de sus elementos constitutivos, suman en total cuatro, y es la falta de homogeneidad en el diseño de estas pocas representaciones lo que permite marcar resoluciones disímiles en base a la comparación con los cánones de camélidos. El motivo documentado en $\mathrm{Ch} 9$ tiene un esquema constructivo caracterizado por un cuerpo alargado dispuesto en forma de "U", de perfil y sin indicación precisa de sus partes. La cola, larga y fina, se muestra como 


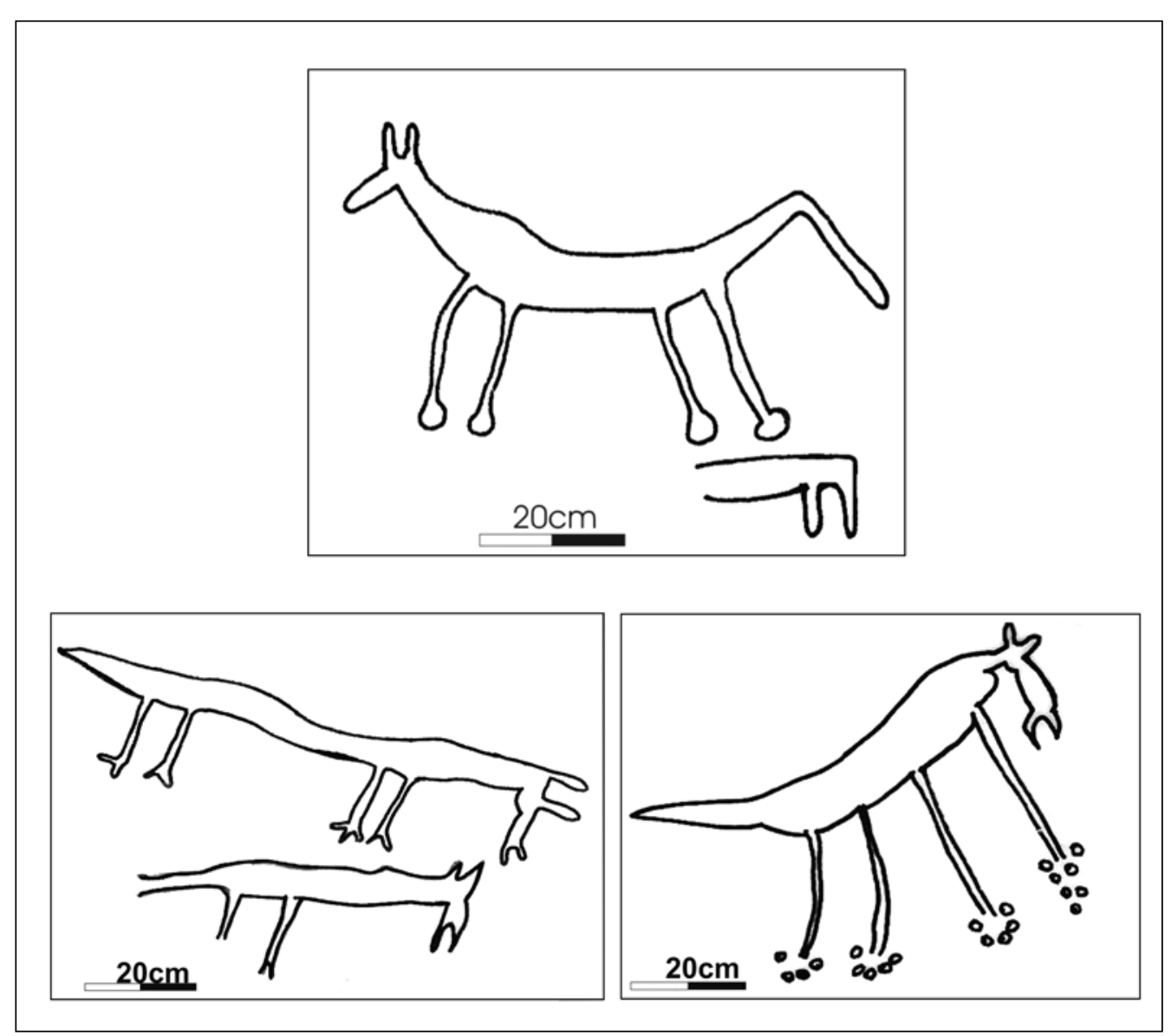

Figura 6. Motivos de equinos identificados en $\mathrm{Ch} 9$ (superior) y en Ch14 (inferior).

Horse motifs identified in $\mathrm{Ch} 9$ (top) and $\mathrm{Ch} 14$ (bottom).

una continuidad del trazo lineal del cuerpo que se afina paulatinamente y se quiebra formando una "V" invertida. Asimismo, están indicadas las cuatro extremidades y la cabeza, en la cual se destacan las dos orejas. Es precisamente en la culminación de las patas traseras y delanteras donde se distinguen los cuatro cascos del caballo, señalados por medio de círculos (Figura 6).

En tanto en Ch14 se han documentado tres motivos que tienen un diseño alargado y esquematizado, que simplifica la imagen del caballo dado que cabeza, cuerpo y cola están ejecutados a partir de un solo trazo. En este modelo constructivo sólo el cuerpo del animal está de perfil. Las patas están ubicadas de manera aleatoria a lo largo del esquema lineal en el que se resuelve la figura (Figura 6). El detalle a resaltar es la forma de la cabeza que presenta algunos rasgos como la quijada y el hocico que no se corresponden con las resoluciones de los camélidos y que, por el contrario, son propios del caballo.
No obstante, nuevamente aquí es factible establecer diferencias en la culminación de las extremidades de estos tres motivos. Dos representaciones conservan algunas características de los camélidos, ya que tienen dos o tres dedos en sus patas anteriores y posteriores; en tanto en otro fueron reemplazados por los cascos, confeccionados a partir de círculos elaborados por medio de puntos (Figura 6). Las particularidades de las cuatro figuras equinas respalda la existencia de variaciones de un mismo canon, es decir, su correspondencia con dos patrones de resolución.

\section{La Significación de los Caballos en Charquina}

El análisis de los paneles que presentan las figuras de equinos y su inclusión en el arte rupestre de Charquina en particular, y de Guasapampa en general, permite proponer que los caballos, como rasgos que significan al conquistador español, 
fueron integrados a un universo iconográfico y simbólico dominado por aquellas especies animales que habitaban los paisajes que se integraban a los circuitos de movilidad (i.e. cérvidos, reidos, teidos) de los grupos que ocuparon el área. Como evidencia, los paneles de $\mathrm{Ch} 9$ y específicamente en Ch14 muestran la conjunción de esos elementos reconocidos, significados y vivenciados cotidianamente en el cual la nueva/vieja figura, entendiendo lo viejo como idea anterior o previa en el ideario y no más antigua en cuanto a ejecución, fue incorporada y categorizada con parámetros propios. En este sentido, las similitudes en las tonalidades de los blancos usados en equinos y camélidos, que indican la ejecución sincrónica de ambas figuras, pueden remarcar esta continuidad de sentidos dado que se está realizando lo nuevo en conjunción con lo tradicional.

Este proceso de incorporación de lo novedoso se materializa con mayor fuerza al analizar la figura del camélido que en Guasapampa es el elemento fundamental y estructurante. Este animal posiblemente constituya la base a partir de la cual fue construida la imagen del equino, tal como ya ha sido considerado para otros contextos andinos de contacto (Arenas y Martínez 2009). En este sentido, el análisis de las resoluciones de los caballos autoriza a plantear que, en la definición de su forma, comparte numerosos detalles identificados en el canon D (Figuras 2 y 6), particularidad que admite especificar que los grupos que ejecutaron los paneles seleccionaron para la elaboración del caballo un canon que en $\mathrm{Ch}$ es dominante. Asimismo, y atendiendo a las variaciones mínimas de los elementos constitutivos, las diferencias observadas en las características formales de los equinos se pueden corresponder con los dos patrones presentes en el canon D.

Esta comparación permite destacar claramente aquellos rasgos que se continúan o mantienen y que aluden a la manera en la cual se resuelve la figura del camélido (i.e. la definición lineal que unifica cola, cuerpo, cuello y cabeza, la inserción y distribución aleatoria de las extremidades y la culminación de los dedos en dos de los motivos de Ch14) y aquellos que sugieren al significante desconocido (la forma de la cabeza y quijada del caballo y la culminación de las extremidades con círculos a manera de cascos). Así, este acto de pensar y construir lo novedoso por medio de lo ya significado constituye no sólo un modo de reconocer al otro sino incluso, como plantean Arenas y Martínez (2009), una forma de apropiación simbólica de la otredad.

De la misma manera, la disposición de los soportes en el entorno tampoco muestra diferencias respecto a lo documentado en el marco de la subárea y de Guasapampa. El análisis de los soportes de Ch9 y Ch14 admite distinguir dos situaciones respecto a la observación participativa o privativa de lo representado. No obstante, ambas son el reflejo de las vías diferentes en las que el arte rupestre interactúa con el paisaje y, en este contexto, con las prácticas que se articulan en torno al mismo. Por lo tanto, el nuevo rasgo no modifica la modalidad de hacer visibles o no algunos paneles, ya que mientras que en $\mathrm{Ch} 14 \mathrm{el}$ panel es inaccesible para aquel que circula en el paisaje y desconoce su ubicación (dado que están ejecutados en el interior del tafón), ambos paneles de Ch9 (los camélidos en la cara sur y el equino y el zoomorfo en la norte) permiten una observación directa de los ejecutado.

\section{Consideraciones Finales}

Este rasgo constitutivo y particularizante del "otro", de los españoles, fue apropiado por los indígenas que ocupaban la microrregión del sur de Guasapampa como una manera de pensar y significar lo nuevo a partir de un marco de referencia conocido y comprensible. Otras evidencias de esta continuidad de los esquemas simbólicos son que, por un lado la ejecución de los caballos no implicó abandonar la realización de los otros motivos zoomorfos que están pintados al mismo tiempo o mantenidos y "reactivados" alrededor de estos; de la misma manera, la incorporación de esta figura tampoco generó cambios en cuanto a la manera de organizar y definir las asociaciones de motivos, la disposición en el soporte y, vinculado con este punto, las condiciones de visibilidad/invisibilidad en las que se resuelve todo el arte de Charquina en particular y del sur de Guasapampa en general.

El principio que guía esta reacción generada por la realidad impuesta a partir de la llegada del español es un intento de reproducir prácticas (sociales, representacionales) y significados (relativos al universo de la cultura en general), que en el nuevo contexto generado por la conquista sólo puede lograrse incorporando y resignificando tanto lo propio como lo nuevo (Arenas y Martínez 2009; De Certeau 1999 [1979]). 
En este sentido, el acto de añadir lo desconocido a un marco de comprensión propio se podría interpretar como una estrategia generada por el habitus y la capacidad de los sujetos que persigue reasegurar la reproducción social del grupo, privilegiando la continuidad de los esquemas de percepción (Bourdieu 2002) frente a la imposición de nuevas prácticas y representaciones generadas en y por la conquista.

La ejecución conjunta de equinos y camélidos en un mismo panel respondería a momentos iniciales del contacto en la región, probablemente anteriores a la fundación de la ciudad de Córdoba en 1573, es decir, antes de la implementación plena del régimen colonial que desestructuró a las comunidades indígenas y que implicó una drástica reducción de la movilidad y de las prácticas sociales, culturales, económicas vinculadas a esta. También la inexistencia de iconografía relacionada con el ideario cristiano (i.e. cruces, iglesias o representaciones de personajes religiosos), incorporada a los paneles prehispánicos, constituye otro de los indicadores que da cuenta de la imposibilidad de continuar con esta práctica concreta por parte de los grupos que ocupaban estacionalmente la región de Guasapampa.

La historia nos muestra que esta estrategia de incorporación de la alteridad española como una manera de resistencia a su presencia no fue exitosa a largo plazo, pero lo cierto es que generó el contexto para interpretar un acontecimiento completamente novedoso, al tiempo que permite plantear nuevas líneas de indagación respecto a la multiplicidad de respuestas de los grupos indígenas ante la conquista.

Agradecimientos: Becaria posdoctoral CONICET. A los doctores Eduardo Berberián, Beatriz Bixio y Constanza González Navarro por la lectura crítica del manuscrito y por sus aportes. Asimismo, agradezco las sugerencias realizadas por los evaluadores. Esta investigación se integra al proyecto "Condiciones de posibilidad de reproducción social en sociedades prehispánicas y coloniales tempranas de las Sierras Pampeanas (República Argentina)”, bajo la dirección del Dr. Eduardo Berberián y que cuenta con un subsidio del CONICET (PIP 112200801-02678). Todo lo aquí expuesto es de mi absoluta responsabilidad.

\section{Referencias Citadas}

Arenas, M. y J.L. Martínez 2009. Construyendo nuevas imágenes sobre los Otros en el arte rupestre andino colonial. Revista Chilena de Antropología Visual 13:17-36.

Aschero, C. 1996. ¿Adónde van esos guanacos? En Arqueología. Sólo Patagonia, editado por J. Gómez Otero, pp. 143-152. Centro Nacional Patagónico, Buenos Aires.

Berberián, E., S. Pastor, D. Rivero, M. Medina, A. Recalde, L. López y F. Roldán 2008. Últimos avances de la investigación arqueológica de las Sierras de Córdoba. Comechingonia 11:135-164.

Bixio, B. 1998. Identidades Étnicas en Córdoba del Tucumán: 1573-1700. Tomo 1. Tesis para optar al grado de Doctora, Facultad de Letras, Universidad Nacional de Córdoba, Córdoba.

Bixio, B. y C. González Navarro 2003. Práctica de la justicia y resistencia indígena. CLAHR Colonial Latina American Historical Review 12 (1):1-24.

Bourdieu, P. 2002. Estrategias de reproducción y modos de dominación. Colección Pedagógica Universitaria 37-38:23-42.

Cruz, P. 2006. Mundos permeables y espacios peligrosos. Consideraciones acerca de Punkus y Qaqas en el paisaje altoandino de Potosí, Bolivia. Boletín del Museo Chileno de Arte Precolombino 11:35-50.

De Certeau, M. 1999 [1979]. La Invención de lo Cotidiano. 1 Artes de Hacer. Universidad Iberoamericana, México.
Fernández Distel, A. 1992. Investigación sobre el arte rupestre hispano-indígena del N.O. de la República Argentina. Boletín SIARB 3:199-209.

Gallardo, F., V. Castro y P. Miranda 1990. Jinetes sagrados en el desierto de Atacama: un estudio del arte rupestre andino. Boletín del Museo Chileno de Arte Precolombino 4:27-56.

González Navarro, C. 2009. Una aproximación al territorio indígena prehispánico. Siglos XVI y XVII. Ponencia presentada en XII Jornadas Interescuelas y Departamentos de Historia, Bariloche.

Hastorf, C. 2003. Community with the ancestors: ceremonies and social memory in the middle formative at Chiripa, Bolivia. Journal of Anthropological Archaeology 22:305-332.

Hernández Llosas, M.I. 2001. Arte rupestre del noroeste argentino. Orígenes y contexto de producción. En Historia Argentina Prehispánica, dirigido por Berberián E. y A. Nielsen, Tomo 1, pp. 389-446. Editorial Brujas, Córdoba.

Martínez, J.L. y M.A. Arenas 2009. Problematizaciones en torno al arte rupestre colonial en las áreas centro sur y meridional andina. En Crónicas sobre la Piedra. Arte Rupestre de las Américas, editado por M. Sepúlveda, L. Briones y J. Chacama, pp. 129-140. Ediciones Universidad de Tarapacá, Arica.

Piana, J. 1992. Los Indígenas de Córdoba bajo el Régimen Colonial (1570-1620). Dirección General de Publicaciones de la Universidad Nacional de Córdoba, Córdoba. 
Quejazú Lewis, R. 1992. Introducción. Arte rupestre colonial y republicano de Bolivia y países vecinos. Boletín SIARB 3:6-27.

Recalde, A. 2008-2009. Movilidad estacional y representaciones rupestres. Primeras evidencias de ocupaciones estivales vinculadas con la explotación de ambientes chaqueños en las sierras de Córdoba. Anales de Arqueología y Etnología 63-64:57-80.

- - - 2009. Diferentes entre iguales: el papel del arte rupestre en la reafirmación de identidades en el sur del valle de Guasapampa (Córdoba, Argentina). Boletín del Museo Chileno de Arte Precolombino 14:39-56.
Recalde, A. y C. González Navarro 2010. El arte rupestre como una forma de resistencia a la dominación española en las Sierras Centrales (Córdoba, Argentina). Ponencia presentada en el Coloquio Internacional Vitalidad de las Voces Indígenas: Arte Rupestre del Contacto y en Sociedades Coloniales, Oaxaca.

Trillo, C. 2010. Valoración del Bosque y Conocimiento de las Plantas Silvestres por Parte de los Pobladores de la Sierra de Guasapampa, Noroeste de la Provincia de Córdoba. Tesis para optar al grado de Doctor, Facultad de Ciencias Exactas, Físicas y Naturales, Universidad Nacional de Córdoba, Córdoba

\section{Nota}

1 No obstante, como ya fue analizado para otra área de la provincia (i.e. Cerro Colorado; Recalde y González Navarro 2010), es factible identificar otras formas de resistencia. El arte rupestre puede ser analizado como una vía concreta para oponerse al conquistador y perpetuar las prácticas prehispánicas, y en este sentido constituir una expresión de la resistencia simbólica operada contra la llegada del español. 
